\title{
Ceratite por Staphylococcus aureus após ceratomileuse in situ por laser (LASIK): relato de caso
}

\author{
Staphylococcus aureus keratitis following laser in situ keratomileusis: case report
}

\author{
Alessandra Pinheiro Chaves \\ Paulo Schor \\ Marta Sartori \\ Mauro Campos
}

Trabalho desenvolvido no Setor de Cirurgia Refrativa do Departamento de Oftalmologia.

Escola Paulista de Medicina - Universidade Federal de São Paulo.

Endereço para correspondência: Alessandra Pinheiro Chaves. Rua Francisco Preto, 46, apto. 41. Toledos, Morumbi. São Paulo (SP) Brasil. CEP 05623-010. e-mail:sanchaves@hotmail.com

\begin{tabular}{|l|}
\hline RESUMO \\
\hline Objetivo: Relatar um caso clínico de infecção por $S$. aureus no pós- \\
operatório de LASIK, o tratamento adotado e a evolução clínica. \\
Relato do caso: Paciente de 26 anos, masculino, submetido a \\
LASIK tórico em OE, evoluindo com ceratite por $S$. aureus. Após \\
diagnóstico clínico da infecção, realizamos estudo microbiológico e \\
foi instituída a terapêutica adequada. O paciente evoluiu com recu- \\
peração da transparência corneana e acuidade visual $20 / 25$, sem \\
correção. \\
Discussão: Infecção no pós-operatório de LASIK, quando diagnos- \\
ticada precocemente e tratada adequadamente, pode evoluir sem maio- \\
res complicações e sem comprometimento visual significativo.
\end{tabular}

Palavras-chave: Staphylococcus aureus; Ceratite; Córnea; Ceratomileuse in situ por lase (LASIK).

\section{INTRODUÇÃO}

As ceratectomias fotorrefrativas têm sido amplamente divulgadas e difundidas em todo o mundo, como um tratamento eficaz e seguro, apresentando bons resultados em relação à previsibilidade, estabilidade e reabilitação visual ${ }^{1}$. Até o momento, existem poucos relatos de casos de infecção no pós-operatório das cirurgias refrativas por Excimer laser na literatura mundial ${ }^{3-10}$. O objetivo deste trabalho é relatar a evolução clínica de um paciente acometido por infecção por $S$. aureus no pós-operatório de LASIK, o tratamento adotado e a evolução do caso.

\section{RELATO DE CASO}

A.C.S.N., 26 anos, masculino, contabilista. Paciente avaliado no ambulatório de cirurgia refrativa da Escola Paulista de Medicina, sendo submetido a exame oftalmológico completo, incluindo acuidade visual (AV) com e sem correção, refratometria estática, biomicroscopia, tonometria de aplanação, oftalmoscopia binocular indireta, videoceratografia computadorizada e paquimetria ultra-sônica, sem contra-indicações à cirurgia refrativa. $\mathrm{O}$ paciente negava uso de drogas, bem como doenças sistêmicas. Apresentava refração sob cicloplegia OD: -5,50 DE / -0,75 DC x 90 (20/20) e OE: -5,00 DE / -1,25 DC x 90 (20/20). Foi submetido a LASIK Tórico OE em 03/99, utilizando o Excimer Laser de fluoreto de argônio de 193 nm da empresa americana Summit ${ }^{\circledR}$, modelo Apex Plus ${ }^{\circledR}$ e o microcerátomo da empresa francesa Moria ${ }^{\circledR}$ (Modelo Carriazo Barraquer ${ }^{\circledR}$ ), com disco de aproximadamente $160 \mu$, sendo realizado tratamento de $-5,00 \mathrm{DE} /-1,25$ 
DC x $90^{\circ}$ (elíptico), com zona óptica de 5,0 - 6,5 mm. O ato cirúrgico transcorreu sem intercorrências. Não foi utilizada lente de contato no período pós-operatório. A avaliação à biomicroscopia 30 minutos após o procedimento cirúrgico evidenciava um espaço entre o disco e o estroma de aproximadamente $0,2 \mathrm{~mm}$ na porção inferior, com região temporal e nasal justapostas, sem edema ou dobras significativas.

$\mathrm{O}$ paciente compareceu para avaliação do primeiro PO sem queixas, em uso de colírio com a associação de tobramicina e dexametasona $4 \mathrm{x} / \mathrm{dia}$; à biomicroscopia não foram evidenciados depósitos na interface, edema do disco, dobras ou infiltrados. No terceiro dia pós-operatório o paciente procurou o ambulatório referindo embaçamento visual, dor, hiperemia conjuntival e epífora em OE, sendo observado AV S/C de 20/50, infiltrado de aproximadamente $1 \mathrm{~mm}$ de diâmetro em região temporal superior na incisão da ceratotomia, com edema discreto adjacente, sem reação de câmara anterior (Figura 1). Diante da suspeita de infiltrado infeccioso, realizamos levantamento parcial do flap para coleta de material para estudo microbiológico, cultura e antibiograma; à bacterioscopia foram observados cocos Gram positivos aos pares (Figura 2) sendo iniciados colírios fortificados de sulfato de gentamicina $(15 \mathrm{mg} / \mathrm{ml})$ e cefalotina $(50 \mathrm{mg} / \mathrm{ml})$ de $\mathrm{h} / \mathrm{h}$ no mesmo dia. Após 3 dias de incubação foi evidenciado o crescimento de colônias de $S$. aureus sensível à cefalotina e gentamicina. O paciente evoluiu com melhora do quadro lenta e progressivamente, apresentando estabilização da área infiltrada em $48 \mathrm{~h}$ e início de melhora em $72 \mathrm{~h}$, quando os colírios tiveram a freqüência de instilação reduzida para 4x/dia e foi introduzido dexametasona 0,1\% 3x/dia. Após 15 dias notou-se melhora significativa do quadro, com AV de 20/30P, diminuição da hiperemia, edema e infiltrado, sendo retirados os colírios. Neste período foi possível notar depressão localizada, com afinamento do retalho e estroma subjacente secundário à necrose séptica sem neovascularização. Até 4 semanas após o início do quadro foi notada melhora da transparência corneana, sendo que três meses após o procedimento o paciente apresentava AV de 20/25 com refração sob cicloplegia de +0,50 DE.

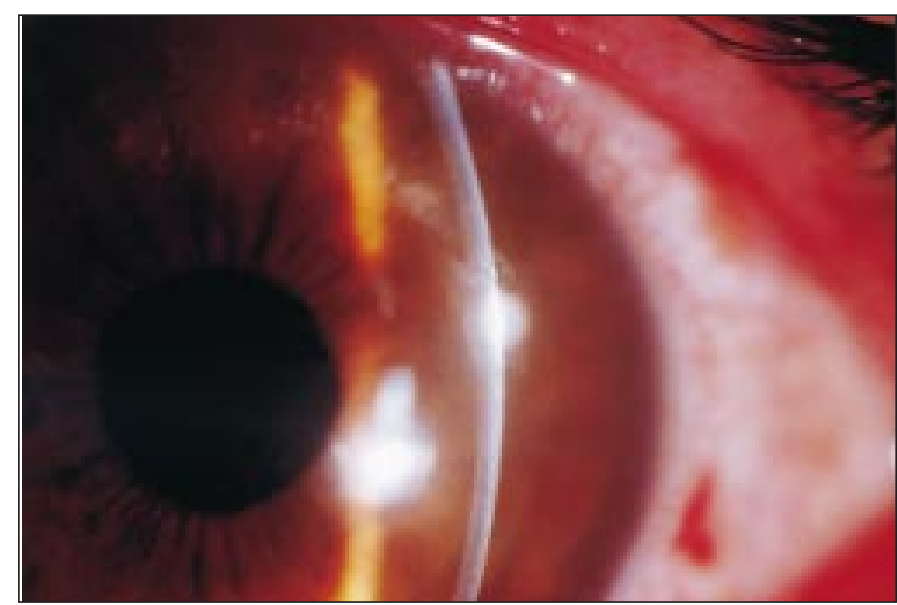

Fig. 1 - Infiltrado corneano com edema adjacente.

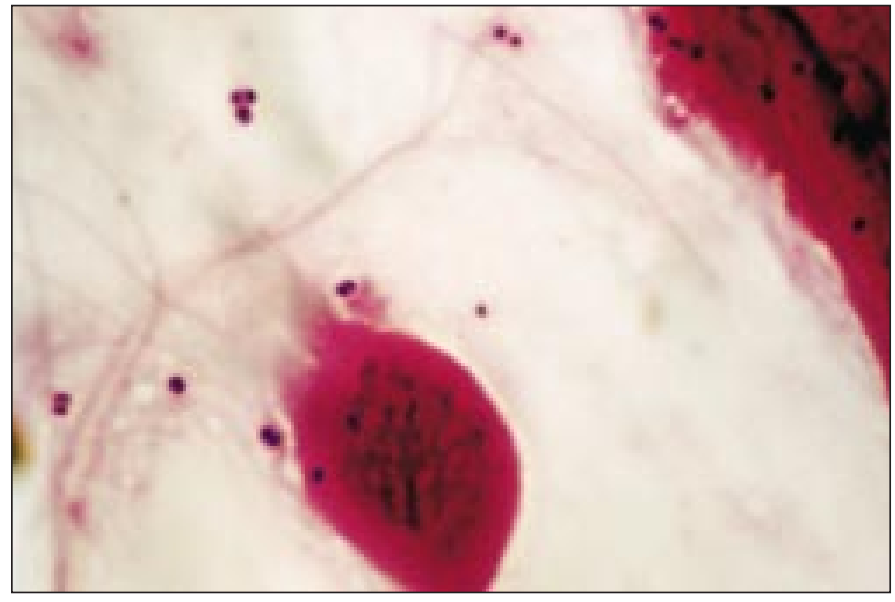

Fig. 2 - Cocos Gram positivos.

\section{DISCUSSÃO}

As complicações mais comuns do LASIK incluem irregularidades no flap, epitelização da interface, astigmatismo regular ou irregular, regressão e hipercorreção. A infecção após cirurgia refrativa, apesar de rara, é uma complicação séria, que requer diagnóstico e tratamento adequados ${ }^{2}$. O paciente apresentado evoluiu sem maiores complicações e com AV final satisfatória após tratamento da ceratite assim como outros casos relatados na literatura, que tiveram em comum o diagnóstico e o tratamento precoces ${ }^{3-5}$.

Quiros et al descreveram 5 casos de ceratite ulcerativa infecciosa após LASIK e sugerem que o uso de lentes de contato e de corticosteróides, olho seco, blefarite e HIV podem representar importante fatores de risco no desenvolvimento da ceratite ulcerativa ${ }^{6}$. Reviglio et al relataram um caso de ceratite por Mycobacterium chelonae 1 mês após LASIK bilateral e simultâneo, sendo observada uma úlcera corneana central associada a edema em OE. Apesar da terapêutica antibiótica instituída e da resposta satisfatória observada inicialmente, o paciente evoluiu para ceratoplastia penetrante, recuperando AV de 20/20 C/C (com correção) ${ }^{7}$. Mulhern et al relataram um caso de endoftalmite por Streptococcus pneumoniae 3 dias após LASIK, evoluindo com AV de 20/25 $\mathrm{C} / \mathrm{C}-4,00$ DE e haze grau 2, sete meses após o tratamento ${ }^{8}$. Pérez-Santonja et al descreveram um caso de infecção por Nocardia asteroides após retratamento realizado no sexto mês PO de LASIK OD. Seis meses após a segunda intervenção e tratamento específico sistêmico e tópico, o paciente apresentava AV de 20/40 C/C e discreta cicatriz na área central da córnea ${ }^{9}$. Nascimento et al relataram outro caso de ceratite por Nocardia asteroides após troca do disco OE no $5^{\circ}$ mês PO LASIK bilateral e simultâneo, devido a edema severo do flap. Foi realizada remoção do segundo disco 4 semanas após a última intervenção; após tratamento específico, o paciente apresentava AV de 20/60 C/C e cicatriz estromal paracentral ${ }^{10}$.

Em qualquer procedimento cirúrgico refrativo, quando há quebra da barreira epitelial, há o risco de infecção. É fundamental 
que os cirurgiões façam uma avaliação pré-operatória completa e estejam familiarizados com a técnica cirúrgica. Este caso reforça a importância do diagnóstico e da terapêutica precoces das infecções pós LASIK para que resultados satisfatórios sejam alcançados, visando à prevenção de complicações como endoftalmite, úlceras de córnea e opacidades corneanas.

\section{SUMMARY}

Purpose: To report a case of S. aureus keratitis after laser in situ keratomileusis, the management and the outcome.

Case report: 26-year-old male underwent toric LASIK OS, evoluing with S. aureus keratitis. After a clinical hypothesis of infection, we performed corneal scrape for lab analysis and proper treatment was given. After successful treatment, the patient showed an improvement in corneal transparency and recovered his visual acuity.

Discussion: Infections following laser in situ keratomileusis may not produce visual loss if proper treatment is given.

Keywords: Staphylococcus aureus; Keratitis; Cornea; Laser in situ keratomileusis (LASIK).

\section{REFERÊNCIAS BIBLIOGRÁFICAS}

1. Mori E, Suzuki C, Alleman N, Schor P, Campos M, Chamon W. Ceratectomia fotorrefrativa associada à ceratotomia lamelar pediculada (LASIK) para correção de miopia e astigmatismo moderados e altos em um serviço universitário. Arq Bras Oftal 1998;60:585-9.

2. Wilson SE. LASIK: management of common complications. Laser in situ keratomileusis. Cornea 1998;17:5,459-67.

3. AL Reefy M. Bacterial keratitis following laser in situ keratomileusis for hyperopia. J Refract Surg 1999;15:2,216-7.

4. Webber SK, Lawless MA, Sutton GL, Rogers CM. Staphylococcal infection under a LASIK flap. Cornea 1999;18:3,361-5.

5. Aras C, Ozdamar A, Bahcecioglu H, Sener B. Corneal interface abscess after laser in situ keratomileusis. J Refract Surg 1998;14,156-7.

6. Quiros PA, Chuck RS, Smith RE, Irvine JA, Chao L, McDonnell PJ. Infectious Ulcerative Keratitis After Laser In Situ Keratomileusis. Arch Ophthalmol 1999; 117:10,1423-7.

7. Reviglio V, Rodriguez ML, Picotti GS, Paradello M, Luna JD, Juárez CP. Mycobacterium chelonae keratitis following laser in situ keratomileusis. J Refract Surg 1998;14:3,357-60.

8. Mulhern MG, Condon PI, Okeefe M. Endophthalmitis after astigmatic myopic laser in situ keratomileusis. J Refract Surg 1997;23:6,948-50.

9. Pérez Santonja JJ, Sskla HF, Abad JL, Zorraquino A, Esteban J, Alió JL. Nocardial keratitis after laser in situ keratomileusis. J Refract Surg 1997; 13:3,314-7.

10. Nascimento EG, Carvalho MJ, De Freitas D, Campos M. Nocardial keratitis following myopic keratomileusis. J Refract Surg 1995;11:3,210-1. 